\title{
THỬ NGHIẸM DỰ BÁO TỔ HỢP HẠN MÙA TRƯỜNG NHIÊT Độ MÙA ĐÔNG TRÊN KHU VỰC BẮC BỘ DỰA TRÊN CÁCH TIẾP CẬN ĐA VẬT LÝ VÀ TRUNG BİNH TRẼ
}

\author{
Võ Văn Hòa ${ }^{1}$, Dư Đức Tiến ${ }^{2}$, Mai Khánh Hưng ${ }^{2}$, \\ Lương Thị Thanh Huyền'², Đặng Đình Quân²
}

Tóm tắt: Nghiên cứu khảo sát dụ báo nhiệt độ hạn mùa vào mùa đông trên khu vục Bắc Bộ bằng mô hình khí hậu khu vục RegCM phiên bản 4.6.1. Các khảo sát đánh giá các kết quả dụ báo do ảnh hương của việc sử dụng các sơ đồ tham số hóa vật lý khác nhau của mô hình RegCM, gồm sơ đồ bề mặt BATS và CLM4.5, so đồ bưc xạ RRTM và CCRM và so đồ đối lưu Grell, Kain-Friscth và Tiedkle. Điều kiện biên sử dụng là mô hình CFS phiên bản 2 của NCEP (Mỹ) thời đoạn 2011-2018. Các kết quả được đánh giá trực tiếp với các quan trắc của Việt Nam trong giai đoạn này cho thấy: i) kết quả dụ báo có độ nhạy lớn nhất đối với sụ thay đổi sơ đồ bề mặt; ii) trong khi BATS có xu thế dụ báo sai số thiên âm, sư dụng CLM4.5 có xu thế dụ báo thiên dương. Sai số dụ báo nhiệt độ trung bình các tháng mùa đông còn lớn ở tất cả các cấu hình vật lý thử nghiệm, tuy nhiên với hệ số tuong quan cao cho tùng vùng khí hậu cho thấy khả năng áp dụng các phưong pháp hiệu chỉnh thông kê ở các nghiên cứu tiếp theo. Ngoài ra, việc tổ hợp các 12 dụ báo khác nhau cũng cho phép có kết quả với sai số giảm hơn so với việc sủ dụng tùng dụ báo đơn lẻ.

Tù̀ khóa: Mô hình RegCM, dụ báo tổ hợp hạn mùa, nhiệt độ mùa đông Bắc Bộ.

Ban Biên tập nhận bài: 12/04/2020 ～Ngày phản biện xong: 20/06/2020 Ngày đăng bài: 25/06/2020

\section{Mở đầu}

So với dự báo cảnh báo cực ngắn, dự báo thời tiết hạn đến 10-15 ngày, bài toán dự báo tại các hạn dự báo xa hơn như tháng, mùa, năm, thập kỉ và nhiều thập kĩ có những đặc trưng khá khác nhau. Các hạn dự báo xa hơn liên quan đến những hiểu biết và khả năng mô phỏng các nhân tố tác động chính cả bên trong (internal) lẫn bên ngoài (external) ứng với từng quy mô thời gian nhất định $[1,2]$. Hạn tháng, mùa có thể kể đến các dao động, tương tác khí quyển-đại dương có quy mô cỡ lục địa (ENSO, MJO...). Đối với các dự báo cỡ nhiều năm, thập kỉ, nhiều thập kỉ (dự tính khí hậu) sẽ liên quan cả đến khả năng mô phỏng dự báo các nhân tố bên ngoài như hoạt động của Mặt trời, tác động của con người đến

${ }^{1}$ Đài Khi tượng Thủy văn khu vực đồng bằng Bắc Bộ ${ }^{2}$ Trung tâm Dư báo Khi tương Thủy văn quốc gia Email:vovanhoa80@yahoo.com cấu trúc hóa học, vật lý của hệ sinh thái của Trái Đất (biến đổi khí hậu). Dự báo ở các hạn này đều dựa trên các mô hình gắn kết đầy đủ từ khí tượng, hải văn đến băng quyển và các quá trình tại bề mặt Trái Đất, có độ phân giải chi tiết theo không gian khoảng từ 50-100km². Độ chính xác đối với hạn dự báo dài còn hạn chế tuy nhiên những xu thế dự báo đã bước đầu cho phép ứng dụng được trong công tác đưa ra các giải pháp, chính sách trong hoạt động kinh tế-xã hội để thích ứng tùy thuộc từng hệ quả được cảnh báo đưa ra [3].

Các phương pháp dự báo hạn mùa trong nghiệp vụ hiện nay vẫn được tiếp cận bằng phương pháp thống kê và bằng phương pháp mô hình số/mô hình động lực. Cách tiếp cận bằng mô hình động lực có thể sử dụng trực tiếp sản phẩm của mô hình khí hậu toàn cầu (GCM) hoặc lồng (nest) các mô hình khí hậu khu vực (RCM) vào các $\mathrm{GCM}$ dựa trên nguyên tắc hạ qui mô 
động lực và phần nào đã thể hiện những ưu điểm vượt trội trong khả năng cung cấp sản phẩm dự báo [3]. Ưu điểm của việc lồng các $R C M$ vào các GCM là đã mô tả chi tiết hơn các quá trình địa phương và khu vực. Mặc dù vậy, độ chính xác của kết quả dự báo ngoài việc phụ thuộc vào điều kiện biên của GCM còn phụ thuộc vào chính năng lực của các RCM thông qua bản chất động lực và các sơ đồ tham số hóa [4,5].

Ở Việt Nam, từ những năm 2000, trong khuôn khổ đề tài cấp Tổng cục Khí tượng Thủy văn trước đây do Nguyễn Duy Chinh (Viện Khoa học Khí tượng Thủy văn và Môi trường) làm chủ nhiệm, sử dụng mô hình thống kê để xây dựng hệ thống dự báo này là dị thường tổng lượng mưa mùa và nhiệt độ trung bình mùa (tổng hoặc trung bình từng 3 tháng liên tiếp nhau) [1]. Các ứng dụng mô hình RCM đã được thử nghiệm tại Việt Nam từ những năm 2005 cho thấy tiềm năng ứng dụng cao [7]. Liên quan đến áp dụng trong nghiệp vụ dự báo khí hậu sử dụng phương pháp mô hình số gần đây có thể kể đến công trình nghiên cứu cấp Nhà nước KC08.29/06-10 "Nghiên cứu tác động của biến đổi khí hậu toàn cầu đến các yếu tố và hiện tượng khí hậu cực đoan ở Việt Nam, khả năng dự báo và giải pháp chiến lược ứng phó”, Phan Văn Tân và cộng sự (2010) [8] đã bước đầu ứng dụng thành công hệ thống mô hình kết hợp đại dương - khí quyển CAM-SOM chạy dự báo hạn mùa cung cấp đầu vào cho các mô hình khí hậu khu vực trong điều kiện Việt Nam.

Với ưu điểm của các RCM trong vấn đề dự báo khí hậu và khả năng chi tiết hóa chế độ khí hậu bề mặt, nghiên cứu sẽ thử nghiệm dự báo hạn mùa (đến 6 tháng) bằng mô hình RegCM vào mùa đông cho khu vực Bắc Bộ, giai đoạn 2011-2018. Toàn bộ thông tin về mô hình nghiên cứu, dữ liệu quan trắc, điều kiện biên và thiết kế thử nghiệm được trình bày trong mục 2 . Mục 3 là kết quả đạt được và một số kết luận chính được đưa ra trong mục 4.

2. Mô hình nghiên cứu, dữ liệu quan trắc, điều kiện biên và thiết kế thử nghiệm

\subsection{Mô hình nghiên cứu và điều kiện biên}

Nghiên cứu sử dụng phiên bản 4.6.2 của mô hình RegCM [9], kí hiệu là RegCM4. Phiên bản RegCM đầu tiên được xây dựng dựa trên MM4 (Mesoscale Model Version 4) của Trung tâm quốc gia nghiên cứu khí quyển (NCAR) và Trường đại học Tổng hợp Pennsylvania (PSU), Hoa Kỳ, vào cuối những năm 1980. Các thông tin về sơ đồ vật lý trong RegCM gồm: sơ đồ bề mặt gồm sơ đồ trao đổi sinh - khí quyển (Biosphere Atmosphere Transfer Scheme - BATS) và sơ đồ mô hình bề mặt cộng đồng CLM (Community Land Model), sơ đồ sơ đồ truyền bức xạ của NCAR-CCM (CCRM) và mô hình truyền bức xạ RRTM, sơ đồ đối lưu mây tích gồm của Grell, Kain-Friscth và Tiedkle.

Trong nghiên cứu sẽ sử dụng mô hình CFS phiên bản số 2 (Climate Forecast System) [10] của Trung tâm Dự báo môi trường Hoa Kỳ (NCEP) làm điều kiện biên. Hiện tại CFS đã được phát triển đến phiên bản số 2 , được chạy 4 lần/ngày $(00,06,12,18$ giờ UTC) với hạn dự báo 9 tháng trên hệ thống tính toán của NCEP. Kết quả dự báo CFS được cung cấp miễn phí cho cộng đồng có hạn dự báo 6 tháng (cộng ngày đầu tiên của tháng thứ 7 ) và được lưu trữ trên máy chủ của NCEP trong vòng 7 ngày gần với phiên dự báo hiện tại (http://nomads.ncep.noaa.gov/pub/data/nccf/co $\mathrm{m} / \mathrm{cfs} / \mathrm{prod} / \mathrm{cfs} /$ ).

\subsection{Dũ liệu quan trắc}

Số liệu nhiệt độ của các trạm quan trắc khí tượng bề mặt trên khu vực Bắc Bộ được thu thập trong giai đoạn 2011 đến 2018 để phục vụ đánh giá dự báo từ mô hình RegCM. Danh sách các trạm được đưa ra trong Bảng 1 và đã bao gồm cả phân loại theo các vùng khí hậu địa phương (R1 - Tây Bắc, R2 - Việt Bắc và Đông Bắc và R3 - Đồng Bằng Bắc Bộ). Nhiệt độ trung bình tháng là nhiệt độ trung bình của tất cả nhiệt độ trung bình ngày trong tháng được đánh giá. Các chỉ số đánh giá gồm sai số trung bình (ME), trung bình tuyệt đối (MAE) và trung bình tuyệt đối quân phương (RMSE). 


\section{BÀI BÁO KHOA HỌC}

Bảng 1. Thông tin các trạm quan trắc úng với các vùng khí hậu thuộc Bắc Bộ Việt Nam

\begin{tabular}{|c|c|c|c|c|c|c|c|c|c|c|c|}
\hline \multicolumn{3}{|c|}{ R1 - Tây bắc } & \multicolumn{6}{|c|}{ R2 - Việt Bắc-Đông Bắc } & \multicolumn{3}{|c|}{ R3 - Đồng Bằng Bắc Bộ } \\
\hline Name & Lat. & Lon. & Name & Lat. & Lon. & Name & Lat. & Lon. & Name & Lat. & Lon. \\
\hline Muong Te & 22.37 & 102.83 & Hiep Hoa & 21.35 & 105.97 & Dong Van & 23.25 & 105.27 & $\mathrm{Ba} \mathrm{Vi}$ & 21.15 & 105.42 \\
\hline $\mathrm{Sin} \mathrm{Ho}$ & 22.37 & 103.23 & Bac Ninh & 21.18 & 106.08 & $\mathrm{Sa} \mathrm{Pa}$ & 22.35 & 103.82 & Ha Dong & 20.97 & 105.75 \\
\hline Tam Duong & 22.42 & 103.48 & $\mathrm{Bac} \mathrm{Me}$ & 22.73 & 105.37 & Lao Cai & 22.5 & 103.97 & Chi Linh & 21.08 & 106.38 \\
\hline Muong La & 21.52 & 104.03 & Bao Lac & 22.95 & 105.67 & Ha Giang & 22.82 & 104.97 & Son Tay & 21.13 & 105.5 \\
\hline Than Uyen & 21.95 & 103.88 & Bac Quang & 22.5 & 104.87 & That Khe & 22.25 & 106.47 & $\mathrm{Ha}$ Noi & 21.03 & 105.8 \\
\hline Muong Lay & 22.07 & 103.15 & Luc Yen & 22.1 & 104.78 & Cao Bang & 22.67 & 106.25 & Phu Ly & 20.55 & 105.92 \\
\hline Phieng Lanh & 21.85 & 103.57 & Pho Rang & 22.23 & 104.47 & Vinh Yen & 21.32 & 105.6 & Hung Yen & 20.65 & 106.05 \\
\hline Tuan Giao & 21.58 & 103.42 & Chiem Hoa & 22.15 & 105.27 & Yen Bai & 21.7 & 104.87 & Nam Dinh & 20.39 & 106.15 \\
\hline Pha Din & 21.57 & 103.5 & Cho Ra & 22.45 & 105.73 & Phu Lien & 20.8 & 106.63 & Ninh Binh & 20.23 & 105.97 \\
\hline Song Ma & 21.5 & 103.75 & Nguyen Binh & 22.65 & 105.9 & Lang Son & 21.83 & 106.77 & Hai Duong & 20.93 & 106.3 \\
\hline Co Noi & 21.13 & 104.15 & Ngan Son & 22.43 & 105.98 & Thai Nguyen & 21.6 & 105.83 & Van Ly & 20.12 & 106.3 \\
\hline Yen Chau & 21.05 & 104.3 & Van Chan & 21.58 & 104.52 & Bai Chay & 20.97 & 107.07 & Nho Quan & 20.32 & 105.73 \\
\hline Bac Yen & 21.23 & 104.42 & Dinh Hoa & 21.92 & 105.63 & Cua Ong & 21.02 & 107.35 & Thai Binh & 20.45 & 106.35 \\
\hline Phu Yen & 21.27 & 104.63 & Bac Son & 21.9 & 106.32 & Tien Yen & 21.33 & 107.4 & Cuc Phuong & 20.25 & 105.72 \\
\hline Moc Chau & 20.83 & 104.68 & Huu Lung & 21.5 & 106.35 & Mong Cai & 21.52 & 107.97 & Hoai Duc & 21.07 & 105.75 \\
\hline Mai Chau & 20.65 & 105.05 & Dinh Lap & 21.53 & 107.1 & $\mathrm{Bac} \mathrm{Ha}$ & 22.53 & 104.28 & & & \\
\hline Dien Bien Phu & 21.37 & 103 & Quang Ha & 21.45 & 107.75 & Hoang Su Phi & 22.75 & 104.68 & & & \\
\hline Son La & 21.33 & 103.9 & Phu Ho & 21.45 & 105.23 & Mu Cang Chai & 21.87 & 104.05 & & & \\
\hline Kim Boi & 20.33 & 105.53 & Tam Dao & 21.47 & 105.65 & Ham Yen & 22.07 & 105.03 & & & \\
\hline Chi Ne & 20.48 & 105.78 & Bac Giang & 21.3 & 106.22 & Minh Dai & 21.02 & 105.05 & & & \\
\hline Son La & 21.33 & 103.9 & Bac Can & 22.15 & 105.83 & Trung Khanh & 22.83 & 106.51 & & & \\
\hline Hoa Binh & 20.82 & 105.33 & Viet Tri & 21.3 & 105.42 & Mau Son & 21.85 & 106.95 & & & \\
\hline Lac Son & 20.45 & 105.45 & Tuyen Quang & 21.82 & 105.22 & Co To & 20.98 & 107.77 & & & \\
\hline & & & Luc Ngan & 21.38 & 106.55 & Hon Dau & 20.67 & 106.8 & & & \\
\hline & & & Son Dong & 21.33 & 106.85 & Bach Long Vi & 20.13 & 107.72 & & & \\
\hline & & & Uong $\mathrm{Bi}$ & 21.03 & 106.75 & & & & & & \\
\hline
\end{tabular}

\subsection{Thiết kế thử nghiệm}

Với mục tiêu khảo sát đánh giá các kết quả dự báo do ảnh hưởng của việc sử dụng các sơ đồ tham số hóa vật lý khác nhau của mô hình RegCM phù hợp với khu vực và yếu tố dự báo cần quan tâm của nghiên cứu, 3 tham số hóa vật lý được khảo sát gồm sơ đồ bề mặt, sơ đồ đối lưu và bức xạ. Bảng 2 đưa ra 12 cấu hình vật lý khác nhau của RegCM trong nghiên cứu này. Dự báo thử nghiệm cho các tháng 12,1 và 2 các mùa đông từ năm 2011 đến 2018, dự báo từ các tháng $7,8,1$ và 10 và mỗi một tháng thực hiện 6 phiên dự báo cách nhau 5 ngày. Các dự báo trung bình tổ hợp từ 12 dự báo với các cấu hình khác nhau của một phiên chạy được gọi là tổ hợp đơn giản, kí hiệu là ENS12. Trong khi lấy trung bình tổ hợp từ 3 phiên chạy liên tiếp được kí hiệu là ENS36.
Bảng 2. Thông tin các thư nghiệm trong nghiên cúu

\begin{tabular}{lccc}
\hline \multirow{2}{*}{ Viết tắt } & \multicolumn{3}{c}{ Cấu hình vật lý trong mô hình } \\
\cline { 2 - 4 } & So đồ bề mặt & Bức xạ & Đối lưu \\
\hline BAT01 & BATS & RRTM & Grell \\
BAT02 & BATS & CCRM & Grell \\
BAT03 & BATS & RRTM & Tiedtke \\
BAT04 & BATS & CCRM & Tiedtke \\
BAT05 & BATS & RRTM & Kain-Fritsch \\
BAT06 & BATS & CCRM & Kain-Fritsch \\
CLM01 & CLM45 & RRTM & Grell \\
CLM02 & CLM45 & CCRM & Grell \\
CLM03 & CLM45 & RRTM & Tiedtke \\
CLM04 & CLM45 & CCRM & Tiedtke \\
CLM05 & CLM45 & RRTM & Kain-Fritsch \\
CLM06 & CLM45 & CCRM & Kain-Fritsch \\
\hline
\end{tabular}




\section{Kết quả}

Hình 1 thể hiện kết quả nhiệt độ trung bình tháng cho từng vùng khí hậu được dự báo từ mô hình RegCM4 với các cấu hình khác nhau, mô hình CFS và kết quả quan trắc thực tế dưới dạng biểu đồ hộp. Dựa vào hình 1 có thể thấy rõ nhiệt độ tháng dự báo bởi mô hình $\mathrm{CFS}$ ở vùng $\mathrm{R} 1$ và R2 đều thấp hơn quan trắc thực tế ở tất cả các hạn dự báo (4 tháng, 5 tháng và 6 tháng). Chỉ riêng với khu vực R3, giá trị nhiệt độ dự báo trong tháng 1 và tháng 2 xấp xỉ so với quan trắc, đặc biệt tại các hạn dự báo 5 tháng và 6 tháng. Nhìn chung, nhiệt độ trung bình tháng cho vùng $\mathrm{R} 1$ dự báo từ 12 thành phần dự báo riêng lẻ đều có giá trị tiệm cận với quan trắc hơn so với dự báo từ mô hình CFS. Ngoài ra, sai số dự báo của mô hình CFS ở các vùng $\mathrm{R} 1$ và $\mathrm{R} 2$ cao hơn so với cấu hình BATS, trong khi đó CFS cung cấp dự báo tốt hơn RegCM4 ở khu vực R3.
R1
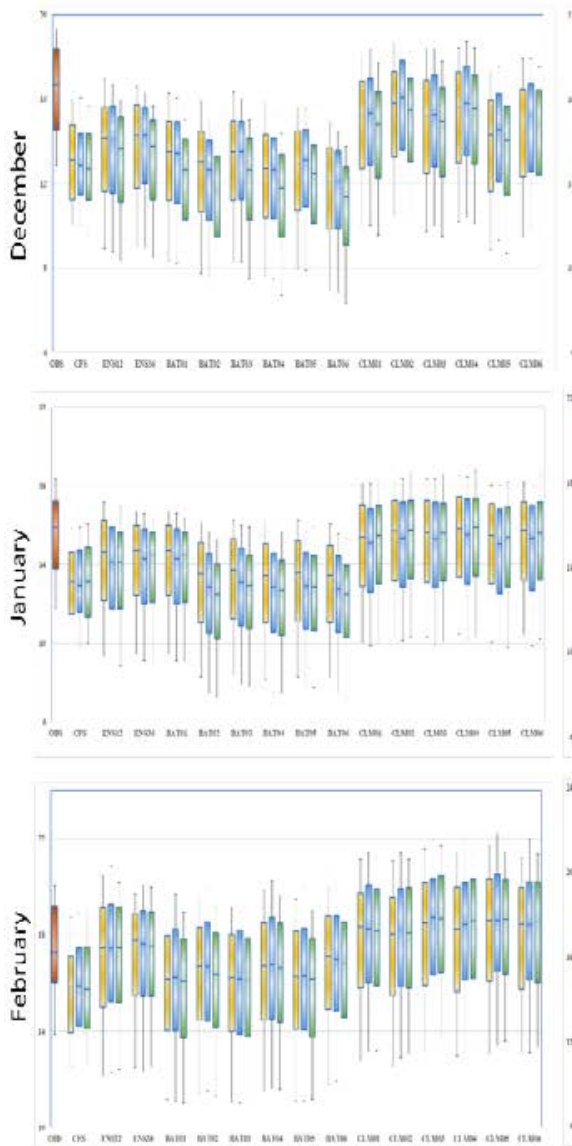

R2
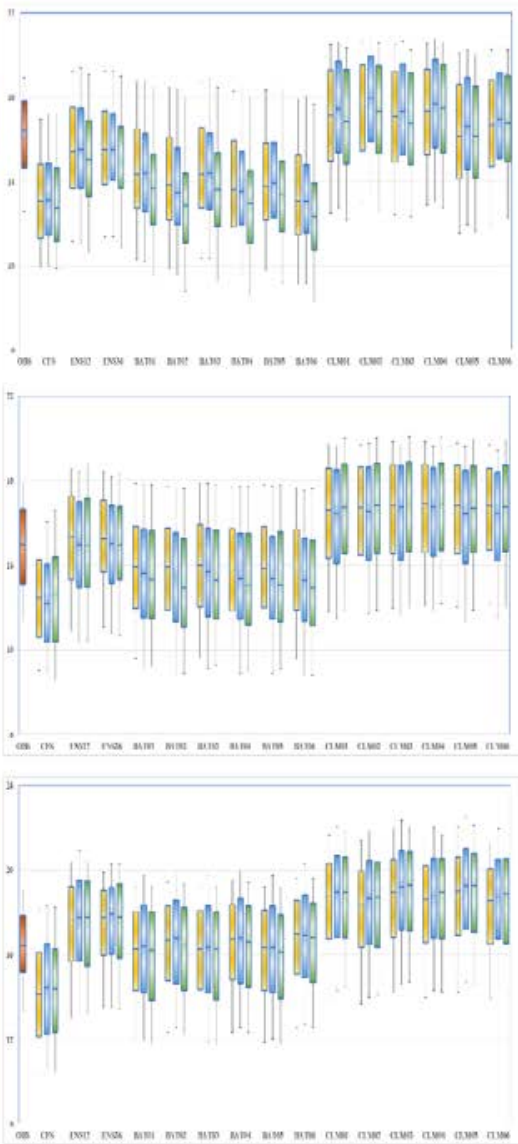

R3
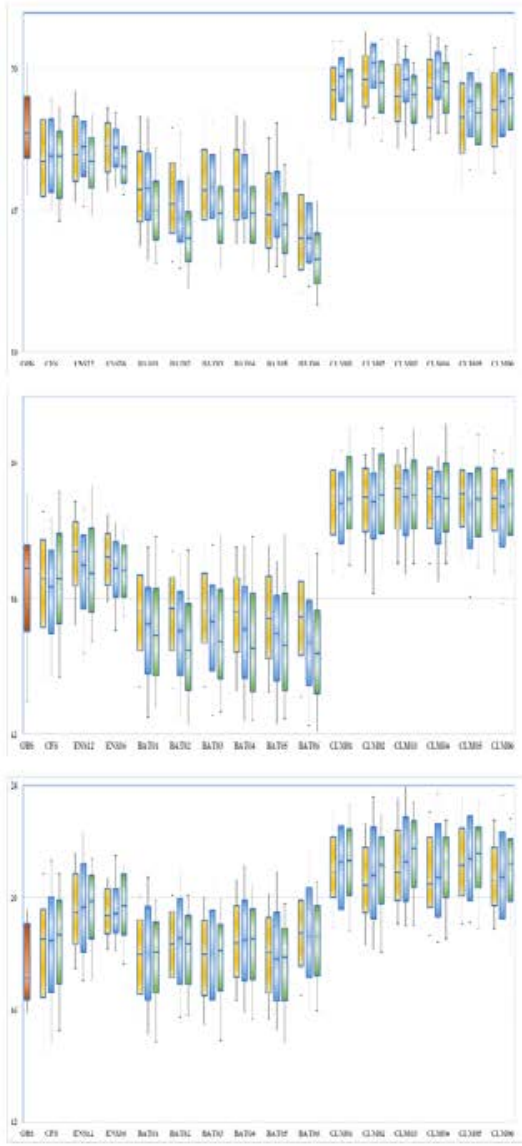

Hình 1. Nhiệt độ trung bình tháng giai đoạn 2011-2018 cho tùng vùng khí hậu R1, R2, và R3 tại các tháng 12, 1 và 2 tù mô hình (CFS), các dư báo sủ dụng BATS, sủ dụng CLM, trung bình tổ hợp tù̀ 12 dụ báo với các cấu hình khác nhau (ENS12), trung bình tổ hợp tù 3 lần chạy liên tiếp (ENS36) tại các hạn 4,5,6 (màu vàng, xanh da trời và xanh lá cây) và quan trắc (đỏ). Biểu đồ hơp thể hiện giá trị phân vị 25 và 75, biểu đồ râu thể hiện phân vị 10 và 90

Từ 12 dự báo đơn lẻ cũng cho thấy khả năng dự báo của mô hình RegCM4 với các cấu hình vật lý khác nhau hầu hết nhạy hơn với sơ đồ tham số hóa mặt đất so với sơ đồ bức xạ hay sơ đồ đối lưu. Đối với khu vực R1, phân bố dự báo sử dụng sơ đồ CLM tiến gần quan trắc hơn so với cấu hình BATS trong tất cả các tháng mùa đông, trong khi tương tự như CFS, BATS có xu hướng đưa ra các giá trị dự báo thấp hơn so với quan trắc. Ở hai khu vực còn lại là $R 2$ và $R 3$, dự báo CLM có thiên hướng dự báo nhiệt độ cao hơn so với dự báo BATS. So sánh dự báo trong 
tháng 1 và tháng 2 , cấu hình BATS có dự báo tốt hơn so với cấu hình CLM. Sự khác biệt giữa các hạn dự báo được thấy rõ rệt nhất trong tháng 12 ở cả hai cấu hình BATS và CLM, đặc biệt ở khu vực $R 2$ và $R 3$.

Đối với dự báo nhiệt độ tháng 12, nhiều trạm đưa ra dự báo thấp hơn so với quan trắc ở cấu hình BATS. Tại các trạm ở vùng núi, sai số có thể lên tới $3-5^{\circ} \mathrm{C}$ do sự chênh lệch lớn giữa độ cao tại điểm lưới mô hình và độ cao trạm thực tế. Với các khu vực đồng bằng ven biển, sự khác biệt giữa cấu hình BATS và CLM cho khu vực R3 là rất lớn, gây ra độ phân tán lớn trong hệ thống ENS12 và ENS36. Xu hướng sai số của cấu hình BATS và CLM được thể hiện trong phân bố sai số trung bình tại từng điểm trạm trong Hình 2 với hạn dự báo 6 tháng cho dự báo tổ hợp từ 12 dự báo vật lý khác nhau.
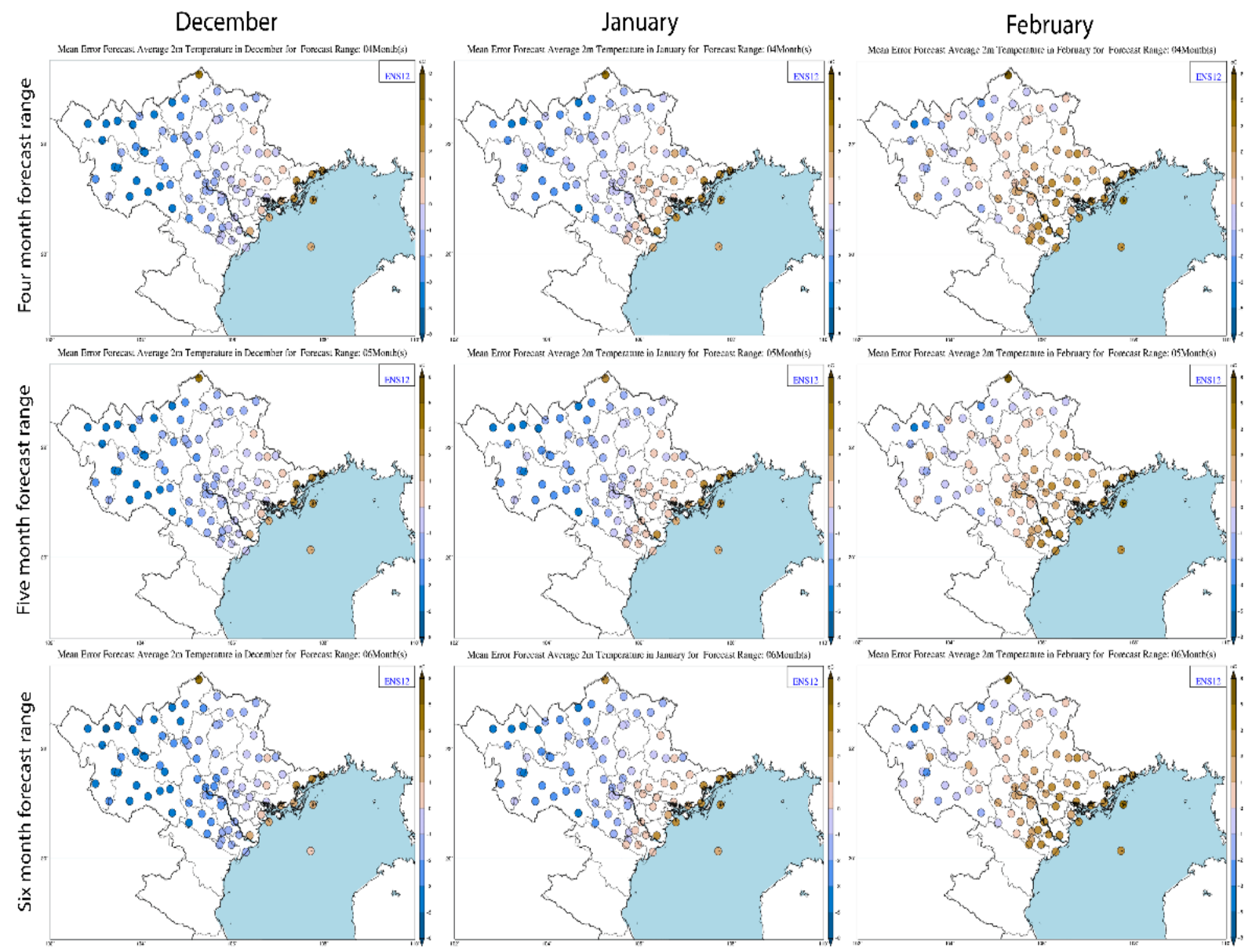

Hình 2. Sai số trung bình (ME) của giai đoạn 2011-2018 tại tùng trạm trên Bắc bộ cho dụ báo tháng 12. 1 và 2 hạn dụ báo 6 tháng cho dụ bảo tổ hợp tù̀ 12 du báo vật lý khác nhau ENS12

Về các sai số dự báo, chỉ số RMSE của dự báo BATS trong khoảng $3,5-4^{\circ} \mathrm{C}$ đối với $\mathrm{R} 1$ và từ $2,3-3,5^{\circ} \mathrm{C}$ đối với $\mathrm{R} 2$ và $\mathrm{R} 3$, trong khi đó con số này đối với dự báo CLM là từ $2,5-3^{\circ} \mathrm{C}$ cho $\mathrm{R} 1$ và $\mathrm{R} 2$, và từ $2,5-4^{\circ} \mathrm{C}$ cho $\mathrm{R} 3$ (Bảng 3 ). Đánh giá thêm về dự báo BATS khi chuyển đồi sơ đồ tham số hóa bức xạ hoặc tích lũy cho thấy, trong $R 1$ và $R 2$ cho các tháng mục tiêu của tháng 12 và tháng 1 , sơ đồ RRTM cung cấp kết quả tốt hơn so với CCRM với mức giảm 10\% - 20\% trong RSME. Độ nhạy trong tháng hai và cho $\mathrm{R} 3$ nhỏ hơn. BATS với sơ đồ KF cho thấy sai số cao hơn so với các sơ đồ GR và TD (RMSE tăng 5\% - 10\%). Đối với CLM, độ nhạy của các sơ đồ bức xạ khác nhau không lớn và rõ ràng như với BATS. Tuy nhiên, sự kết hợp với CCRM có xu hướng sai số thấp hơn so với RRTM.

Việc đánh giá các hệ vật lý khác nhau cho 
thấy sự không chắc chắn trong các dự báo, đặc biệt là với hai quá trình trên mặt đất khác nhau, từ đó tạo điều kiện cho việc tạo ra các khoảng tin cậy của dự báo với RegCM4 cho nhiệt độ mùa đông miền Bắc Việt Nam trong phạm vi dự báo theo mùa.

Trong Hình 1, giá trị trung bình chung của ENS12 và ENS36 được vẽ cùng với các dự báo duy nhất. Đối với vùng cận khí hậu $R 1$, vào tháng 12 , cả ENS12 và ENS36 đều không thể cải thiện dự báo do dự báo sai lệch âm lớn từ các cấu hình BATS. Tuy nhiên, đối với các dự báo tháng 1 và tháng 2 , các dự báo có nghĩa là đồng nhất rõ ràng phù hợp với các biến thể quan sát. Trong các dự báo có nghĩa là đồng nhất, vẫn còn nhiều giá trị dự báo lạnh hơn so với các dự báo. RMSEs (Bảng 3 ) cho $\mathrm{R} 1$ trong tháng 1 và tháng 2 là khoảng $2-3^{\circ} \mathrm{C}$ và thấp hơn so với các dự báo đơn lẻ. Chỉ số RMSE của ENS36 thấp hơn 5\% - 10\% so với ENS12. Đối với $R 2$ và $R 3, R M S E$ đã được cải thiện rõ ràng, khoảng $2-2,5^{\circ} \mathrm{C}$ đối với ENS12 và ENS36 thấp hơn khoảng 20\% so với ENS12. Các bản phân phối ME cho ENS12 trong Hình 3 cho thấy sự cải thiện của ENS12 so với các dự báo đơn lẻ (Hình 3).
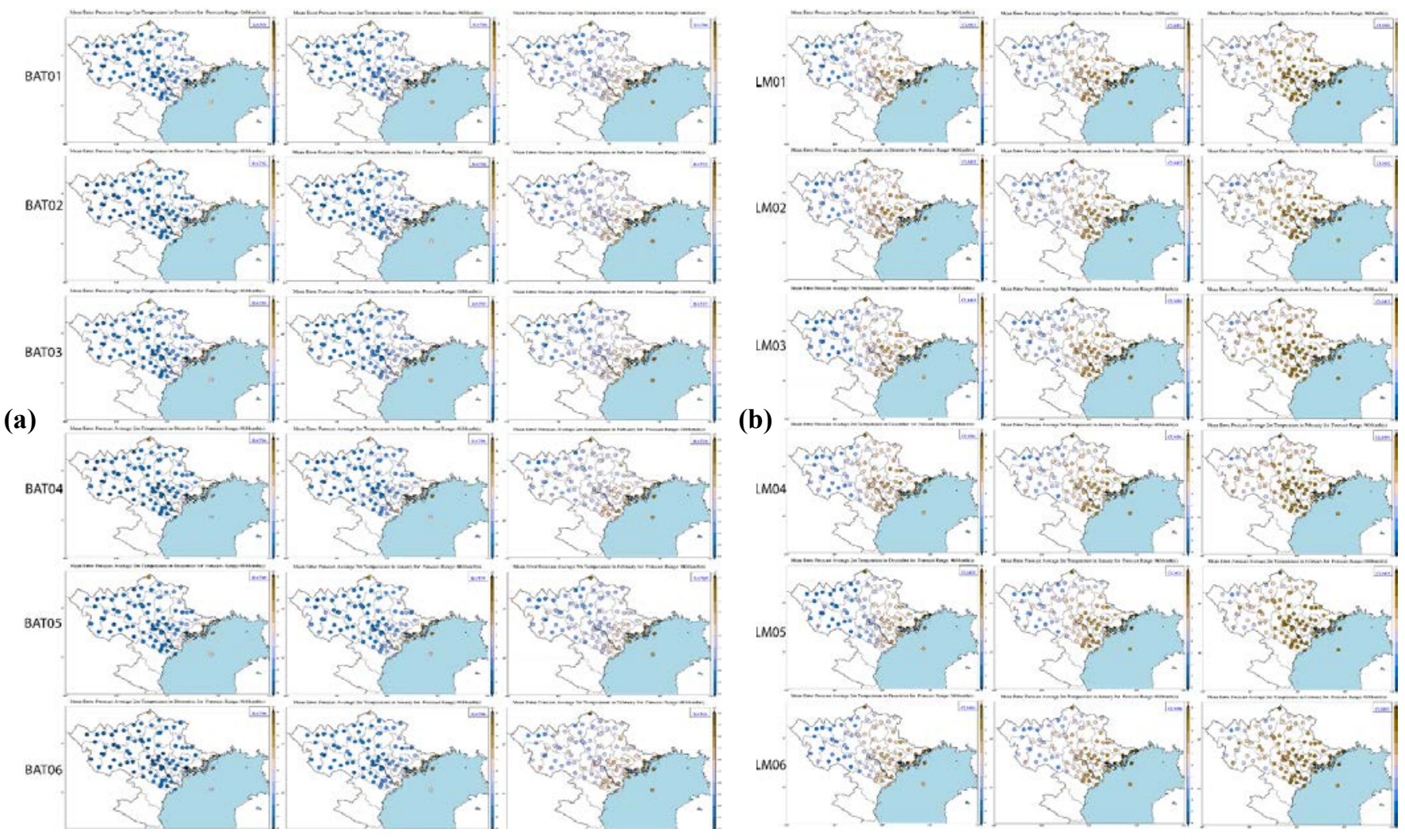

Hình 3. Sai số trung bình (ME) của giai đoạn 2011-2018 tại tùng trạm trên Bắc bộ cho dụ báo tháng 12.1 và 2 hạn dụ báo 6 tháng, đối với 6 dụ báo sủ dụng BATS (a) và sủ dụng CLM (b) 


\section{BÀI BÁO KHOA HỌC}

Bảng 3. Sai số RMSE trong giai đoạn 2011-2018 cho dụ báo nhiệt độ trung bình tháng 12, 1 và 2 của các cấu hình dụ báo khác nhau với hạn dụ báo 4,5,6 tháng tại tùng vùng khí hậu

\begin{tabular}{|c|c|c|c|c|c|c|c|c|c|c|c|c|c|c|c|c|}
\hline Vùng & Tháng & $\begin{array}{c}\text { Hạn dự } \\
\text { báo }\end{array}$ & ENS12 & ENS36 & BAT01 & BAT02 & ВАT03 & BAT04 & BAT05 & BAT06 & CLM01 & CLM02 & CLM03 & CLM04 & CLM05 & CLM06 \\
\hline \multirow{3}{*}{ R1 } & Tháng 12 & 4 & 3,61 & 3,43 & 4,06 & 4,54 & 4,05 & 4,72 & 4,51 & 5,24 & 2,93 & 2,52 & 3 & 2,64 & 3,6 & 3,05 \\
\hline & Tháng 12 & 5 & 3,66 & 3,48 & 4,17 & 4,97 & 4,14 & 4,87 & 4,48 & 5,36 & 2,78 & 2,4 & 2,89 & 2,56 & 3,31 & 2,88 \\
\hline & Tháng 12 & 6 & 4,07 & 3,86 & 4,86 & 5,65 & 4,9 & 5,54 & 5,04 & 6,03 & 3,16 & 2,75 & 3,08 & 2,71 & 3,65 & 3,05 \\
\hline \multirow{3}{*}{$\mathbf{R 2}$} & Tháng 12 & 4 & 2,52 & 2,33 & 3,02 & 3,33 & 3,02 & 3,5 & 3,38 & 3,85 & 2,61 & 2,64 & 2,64 & 2,62 & 2,62 & 2,48 \\
\hline & Tháng 12 & 5 & 2,62 & 2,43 & 3,16 & 3,74 & 3,15 & 3,65 & 3,41 & 4 & 2,62 & 2,83 & 2,73 & 2,79 & 2,62 & 2,57 \\
\hline & Tháng 12 & 6 & 2,75 & 2,53 & 3,64 & 4,2 & 3,67 & 4,16 & 3,83 & 4,54 & 2,57 & 2,71 & 2,51 & 2,65 & 2,52 & 2,48 \\
\hline \multirow{3}{*}{$\mathbf{R 3}$} & Tháng 12 & 4 & 2,13 & 1,86 & 2,92 & 3,27 & 2,92 & 3,54 & 3,53 & 4,14 & 2,4 & 2,57 & 2,41 & 2,45 & 2,24 & 2,21 \\
\hline & Tháng 12 & 5 & 2,29 & 2,04 & 3,16 & 3,83 & 3,15 & 3,72 & 3,56 & 4,32 & 2,5 & 2,85 & 2,57 & 2,7 & 2,29 & 2,36 \\
\hline & Tháng 12 & 6 & 2,42 & 2,12 & 3,69 & 4,4 & 3,8 & 4,41 & 4,05 & 5,01 & 2,34 & 2,55 & 2,13 & 2,43 & 1,94 & 2,17 \\
\hline \multirow{3}{*}{$\mathbf{R} 1$} & Tháng 1 & 4 & 2,68 & 2,51 & 3,41 & 3,56 & 3,39 & 3,6 & 3,49 & 3,6 & 2,3 & 2,15 & 2,2 & 2,08 & 2,22 & 2,06 \\
\hline & Tháng 1 & 5 & 3,09 & 2,8 & 3,87 & 4,13 & 3,86 & 4,07 & 3,96 & 4,16 & 2,59 & 2,46 & 2,51 & 2,32 & 2,64 & 2,42 \\
\hline & Tháng 1 & 6 & 3,08 & 2,77 & 3,99 & 4,4 & 4,03 & 4,29 & 4,09 & 4,47 & 2,33 & 2,22 & 2,3 & 2,14 & 2,41 & 2,25 \\
\hline \multirow{3}{*}{$\mathbf{R 2}$} & Tháng 1 & 4 & 2,17 & 2 & 2,72 & 2,78 & 2,71 & 2,77 & 2,74 & 2,77 & 2,52 & 2,53 & 2,56 & 2,56 & 2,49 & 2,48 \\
\hline & Tháng 1 & 5 & 2,43 & 2,08 & 3,05 & 3,19 & 3,04 & 3,14 & 3,13 & 3,22 & 2,64 & 2,66 & 2,68 & 2,6 & 2,68 & 2,58 \\
\hline & Tháng 1 & 6 & 2,48 & 2,12 & 3,2 & 3,42 & 3,25 & 3,4 & 3,36 & 3,52 & 2,6 & 2,64 & 2,59 & 2,62 & 2,57 & 2,64 \\
\hline \multirow{3}{*}{$\mathbf{R 3}$} & Tháng 1 & 4 & 1,69 & 1,44 & 2,21 & 2,22 & 2,19 & 2,19 & 2,19 & 2,32 & 2,67 & 2,7 & 2,74 & 2,76 & 2,66 & 2,64 \\
\hline & Tháng 1 & 5 & 2,02 & 1,51 & 2,71 & 2,76 & 2,69 & 2,72 & 2,83 & 3 & 2,74 & 2,81 & 2,81 & 2,74 & 2,82 & 2,71 \\
\hline & Tháng 1 & 6 & 2,02 & 1,54 & 2,82 & 3,06 & 2,92 & 3,09 & 3,1 & 3,27 & 2,77 & 2,81 & 2,76 & 2,82 & 2,67 & 2,76 \\
\hline \multirow{3}{*}{ R1 } & Tháng 2 & 4 & 2,84 & 2,39 & 3,14 & 2,91 & 3,14 & 3,08 & 3,22 & 2,84 & 2,81 & 2,86 & 3,04 & 3,02 & 3,05 & 2,85 \\
\hline & Tháng 2 & 5 & 2,75 & 2,27 & 3,2 & 2,95 & 3,21 & 2,99 & 3,2 & 2,82 & 2,71 & 2,79 & 2,86 & 2,81 & 2,85 & 2,83 \\
\hline & Tháng 2 & 6 & 2,66 & 2,5 & 3,19 & 3,03 & 3,18 & 2,94 & 3,19 & 2,81 & 2,69 & 2,71 & 2,81 & 2,75 & 2,73 & 2,81 \\
\hline \multirow{3}{*}{$\mathbf{R 2}$} & Tháng 2 & 4 & 2,96 & 2,58 & 2,91 & 2,75 & 2,89 & 2,87 & 2,93 & 2,76 & 3,51 & 3,36 & 3,73 & 3,54 & 3,77 & 3,32 \\
\hline & Tháng 2 & 5 & 2,9 & 2,5 & 2,89 & 2,71 & 2,9 & 2,77 & 2,9 & 2,72 & 3,47 & 3,42 & 3,67 & 3,46 & 3,69 & 3,45 \\
\hline & Tháng 2 & 6 & 2,73 & 2,64 & 2,72 & 2,57 & 2,71 & 2,6 & 2,77 & 2,59 & 3,46 & 3,31 & 3,67 & 3,41 & 3,64 & 3,42 \\
\hline \multirow{3}{*}{$\mathbf{R 3}$} & Tháng 2 & 4 & 3,17 & 2,76 & 2,7 & 2,62 & 2,69 & 2,79 & 2,73 & 2,79 & 4,11 & 3,84 & 4,3 & 4,01 & 4,43 & 3,92 \\
\hline & Tháng 2 & 5 & 3,06 & 2,66 & 2,58 & 2,49 & 2,58 & 2,59 & 2,62 & 2,6 & 4,12 & 3,95 & 4,32 & 4 & 4,36 & 3,95 \\
\hline & Tháng 2 & 6 & 2,89 & 2,82 & 2,28 & 2,2 & 2,26 & 2,32 & 2,33 & 2,38 & 4,16 & 3,9 & 4,36 & 3,99 & 4,33 & 4,01 \\
\hline
\end{tabular}

Trong Hình 4, các chỉ số MAE hàng năm của ENS12 ở tất cả các vùng dự báo cho thấy rằng các sai số xảy ra rất lớn trong năm 2012 (đối với năm $2016\left(\mathrm{R} 1, \mathrm{R} 2\right.$ và $\mathrm{R} 3$ với các giá trị $\left.\sim 3-5^{\circ} \mathrm{C}\right)$ và năm 2018 (đối với $\mathrm{R} 1$ có giá trị $\sim 3-4^{\circ} \mathrm{C}$ cho $\mathrm{R} 1$ với các giá trị $\sim 4.5-5.5^{\circ} \mathrm{C}$ cho tháng 12$)$, vào tháng 12).

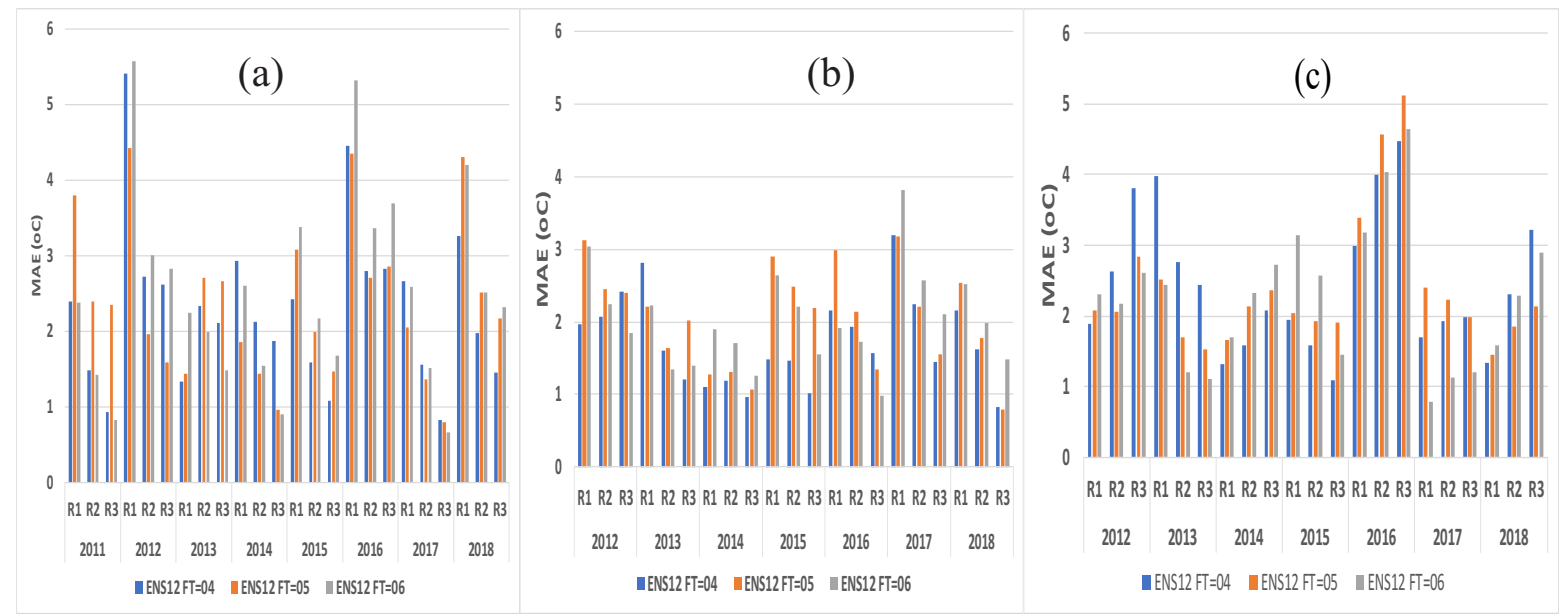

Hình 4. Sai số trung bình tuyệt đối tại tùng năm của trung bình 12 dụ báo (ENS12) với các cấu hình vật lý khác nhau tại tùng vùng ở tùng hạn dụ báo 4.5.6 


\section{Kết luận}

Nghiên cứu đã sử dụng mô hình khí hậu khu vực RegCM phiên bản 4.6.1 trong vấn đề dự báo nhiệt độ hạn mùa vào mùa đông trên khu vực Bắc Bộ giai đoạn 2011-2018. Các kết quả được đánh giá trực tiếp với các quan trắc của Việt Nam trong giai đoạn này cho thấy dự báo có độ nhạy lớn nhất đối với sự thay đổi sơ đồ bề mặt. Việc sử dụng sơ đồ BATS có xu thế dự báo sai số thiên âm còn sử dụng CLM4.5 có xu thế dự báo thiên dương. Việc tổ hợp các 12 dự báo khác nhau cũng cho phép có kết quả với sai số giảm hơn so với việc sử dụng từng dự báo đơn lẻ. Sai số dự báo nhiệt độ trung bình các tháng mùa đông còn lớn ở tất cả các cấu hình vật lý thử nghiệm. Tuy nhiên, với hệ số tương quan cao cho từng vùng khí hậu cho thấy khả năng áp dụng các phương pháp hiệu chỉnh thông kê ở các nghiên cứu tiếp theo.

Lời cảm ơn: các tác giả xin gưi lời cảm on tới đề tài NCKH cấp Nhà nước "Nghiên cứu tác động của biến đổi khi hậu tới sư xâm nhập của các đợt lạnh và nóng ấm bất thường trong mùa đông ở khu vục miền núi phía Bắc phuc vu phát triển kinh tế - xã họi”, mã số BĐKH.25/16-20 đã hỗ trợ để nhóm thực hiện nghiên cưu này. Bài báo này cũng là kết quả thực hiện của một nội dung trong đề tài nói trên.

\section{Tài liệu tham khảo}

1. Kushnir, Y., Scaife, A.A., Arritt, R. et al. (2019), Towards operational predictions of the nearterm climate. Nature Climate Change, 9, 94-101.

2. Smith, D.M., Scaife, A.A., Kirtman, B.P. (2012), What is the current state of scientific knowledge with regard to seasonal and decadal forecasting? Environmental Research Letters, 7(1), 015602. Doi:10.1088/1748-9326/7/1/015602.

3. Fink, A., Langhans, W., Fosser, G., Ferrone, A., Ban, N., Goergen, K., Keller, M., Tölle, M., Gutjahr, O., Feser, F., et al. (2015), A review on regional convection-permitting climate modeling: Demonstrations, prospects, and challenges. Reviews of Geophysics, 53, 323- 361, Doi:10.1002/2014RG000475.

4. Phan Văn Tân, Dư Đức Tiến (2005), Ảnh hưởng của tính bất đồng nhất bề mặt đệm đến các trường nhiệt độ và luợng mưa mô phỏng bằng mô hình RegCM trên khu vục Đông Dương và Việt Nam. Tạp chí khoa học, Đại học Quốc gia Hà Nội, T.XXI, 4, 57-68.

5. Phan Văn Tân, Nguyễn Hướng Điền, Dư Đức Tiến (2005), So đồ BATS và úng dụng trong việc tính các dòng trao đổi năng lượng và nước giữa bề mặt đất - khí quyển. Tạp chí khoa học, Đại học Quốc gia Hà Nội, T.XX, 1, 40-56.

6. Hồ Thị Minh Hà (2008), Nghiên cứu khả năng mô phỏng mùa các yếu tố khí tượng trên lãnh thổ Việt Nam bằng phưong pháp thủy động và thống kê. Luận án Tiến sĩ Khí tượng học, Đại học Khoa học Tự nhiên, ĐHQG Hà Nội.

7. Phan Văn Tân và cộng sự (2008), Nghiên cứu ứng dụng mô hình khí hậu khu vưc mô phỏng/dụ báo mùa các truờng khí hậu bề mặt phục vu qui hoạch phát triển và phòng tránh thiên tai. Báo cáo Tổng kết đề tài QGTĐ.06.05, ĐHQG Hà Nội, 121 trang.

8. Phan Văn Tân và cộng sự (2010), Nghiên cứu tác động của biến đổi khí hậu toàn cầu đến các yếu tố và hiện tượng khi hậu cưc đoan ở Việt Nam, khả năng dư báo và giải pháp chiến luợc ưng phó. Báo cáo tổng kết đề tài NCKH cấp quốc gia, mã số KC08.29/06-10.

9. Gao, X., Giorgi, F. (2017), Use of the RegCM system over East Asia: Review and perspectives. Engineering, 3, 766-772, doi:10.1016/J.ENG.2017.05.019.

10. Saha, S., Moorthi, S., Wu, X., Wang, J., Nadiga, S., Tripp, P., Behringer, D., Hou, Y.T., Chuang, H.Y., Iredell, M., Ek, M. (2014), The NCEP climate forecast system version 2. Journal of Climate, 27, 2185-2208. Doi:10.1175/jcli-d-12-00823.1. 


\title{
APPLICATION OF SEASONAL ENSEMBLE PREDICTION BASED ON MULTIPLE PHYSICAL AND LAGGED-TIME APPROACH TO FORECAST NORTHERN WINTER TEMPERATURE Vo Van Hoa', Du Duc Tien², Mai Khanh Hung', Luong Thi Thanh Huyen ${ }^{2}$, Dang Dinh Quan ${ }^{2}$ \\ ${ }^{1}$ Northern Delta Regional Hydro-Meteorological Center ${ }^{2}$ Vietnam National Center for Hydro-Meteorological Forecasting
}

\begin{abstract}
This study verified the seasonal forecast for winter temperatures in six months for northern Vietnam in 2011-2018 using a regional-climate model (RegCM4) with boundary conditions of coupled-forecast-system model version 2 of the National Centers for Environmental Prediction. In the study, different physical schemes (land-surface processes, cumulus, and radiation parameterizations) in RegCM4 were switched to generate 12 single forecasts. Three sub-climate regions $(R 1, R 2, R 3)$ of northern Vietnam were separately verified with surface observations. Most sensitivity to temperature forecasts is shown by land-surface parameterizations (including biosphere-atmosphere-transfer (BATS) and community-land-model version 4.5 (CLM) schemes) in which BATS forecast groups tend to provide lower temperature forecasts than the actual observations. The CLM's forecast groups tend to forecast higher temperatures. The forecast errors from single forecasts can be clearly reduced with ensemble mean forecasts.
\end{abstract}

Keywords: RegCM model, Northern winter temperature, Seasonal ensemble forecast. 